Creating Productive and Upcoming Sport Education Profesional Hmzanwadi University

Vol.4, No.1, Juni 2021, Hal. 50-54

e-ISSN 2614-8781

\title{
PENERAPAN MEDIA LECTORA UNTUK MENINGKATKAN HASIL BELAJAR MAHASISWA PADA MATA KULIAH PERKEMBANGAN MOTORIK
}

\author{
Achmad Afandi ${ }^{1}$, Ratno Susanto ${ }^{2}$ \\ email: achmad_afandi@budiutomomalang.ac.id ${ }^{1}$, ratnoexecellent@gmail.com $^{2}$ \\ ${ }^{1,2}$ IKIP Budi Utomo Malang
}

\begin{abstract}
Abstrak
Yang melatarbelakangi Penelitian ialah Kurangnya pemahaman Mahasiswa dalam belajar mata kuliah perkembangan motorik. Terjadinya kebosan didalam mata kuliah perkembangan Motorik, kegiatan belajar dan belajar yang monoton Serta karena Mahasiswa yang mengalami kesulitan pada Mata kuliah Perkembangan motorik. Dan perluhnya inovasi dan pengunaan Ilmu pengetahun dan teknologi dalam segi pembelajaran. Dikarenakan Pembelajaran Kurang kereatif dan Inovatif. Untuk itu tujuan penelitian agar pembelajaran matakuliah motorik menarik, praktis digunakan dan proses pembelajaran berjalan dengan baik. Penelitian ini mengunakan metode penelitian Tindakan Kelas (PTK) dengan melalui 4 tahapan penelitian yaitu di singkat dengan nama (4 D) perencanaan, tindakan, pengamatan dan refleksi.terdapat dua siklus. Penelitian ini membuktikan adanya peningkatan dengan mengunakan aplikasi Lectora bagi mahasiswa tahun ajaran 2019/2020. Dapat diketahuivalidasi ahli materi sebesar 90,75\%., ahli media dengan total nilai sebesar 84,03\%, Uji coba kelompok kecil.Hasilnya 86,85 dengan rata-rata kelayakan adalah $87.21 \%$ termasuk dalam kategori "sangat valid". Sehingga seluruh mahasiswa telah tuntas dan mencapai SKM yang ditentukan.hasilnya terdapat jumlah peningkatan.
\end{abstract}

Kata kunci: Lectora Inspire, Hasil Belajar, Motorik

\begin{abstract}
The background of the research is the lack of understanding of students in learning motor development courses. The occurrence of boredom in the Motor development course, monotonous learning and learning activities and because students have difficulty in motor development courses. And the need for innovation and the use of science and technology in terms of learning. Due to Less creative and innovative learning. For this reason, the aim of research is that learning motoric subjects is interesting, practical to use and the learning process goes well. This research uses the Class Action Research (CAR) method by going through 4 stages of research, namely in short by the name $(4 \mathrm{D})$ planning, action, observation and reflection. There are two cycles. This research proves an increase by using the Lectora application for students in the 2019/2020 school year. It can be seen that the validation of material experts is 90,75\%., Media experts with a total score of $84.03 \%$, small group trials. The result is 86.85 with an average feasibility of $87.21 \%$ including in the "very valid" category. So that all students have completed and achieved the specified SKM. The result is an increase.
\end{abstract}

Keywords: LectoraInspire, Learning Outcomes, Motor 
Creating Productive and Upcoming Sport Education Profesional Hmzanwadi University

Vol.4, No.1, Juni 2021, Hal. 50-54

e-ISSN 2614-8781

\section{A. Pendahuluan}

Pendahuluan di Kampus IKIP Budi Utomo terdapat mata kuliah perkembangan motorik. Mata kuliah tersebut sangat berpengaruh kepada mahasiswa terutama untuk menunjang mata kuliah yang lain dan sangat baik untuk mereka saat setelah lulus nanti. Gerakan motorik dibagi menjadi 2 yakni motorik kasar dan motorik halus (Mahfud \& Fahrizqi, 2020). Sangat banyak aktivitas manusia yang melibatkan dimensi keterampilan motorik (Mustafa \& Sugiharto, 2020), misalnya dunia olahraga, dunia seni, serta beragam dunia kerja, dan profesi lainnyaKarena di dunia kerja dalam bidang pendidikan terutama untuk seorang guru. Karena didalam mata kuliah perkembangan motorik mencakup 3 rana yaitu afektif, kognitif dan psikomotorik. Akan tetapi di zaman sekarang IPTEK sangat berkembang pesat. Di dalam pembelajaran dikelas mahasiswa banyak yang mengalami kebosanan didalam pembelajaran, dikarenakan minat baca kurang. Dan pembelajaran terdahulu kurang I berinovasi terlebih sekarang telah terjadi pandemik covid-19. Maka dari itu solusi yang di tawarkan dengan menggunakan aplikasi Lectora agar proses pembelajaran dapat berjalan dengan Maksimal Pada Mata Kuliah Perkembangan Motorik "hasil pembelajaran adalah salah satu indikator lebih banyak ditentukan mutu pendidikan (Kusumah et al., 2020). lectora inspire adalah program yang inovasi dan efesien untuk media pembelajaran (Shalikhah, 2017). Lectora Inspire adalah aplikasi pengembangan belajar Simple dalam penggunaanya (Pengembangan Media Lectora Inspire Dengan Pendekatan Kontekstual Pada Siswa Sma Kelas X | Zuhri | Pythagoras: Jurnal Program Studi Pendidikan Matematika, n.d.). Lectora digunakan untuk membuat kursus online pelatihan, penilaian, dan presentasi (Dewi et al., 2020). Penilaian hasil belajar merupakan komponen penting didalam kegiatan pembelajaran (Noor, 2020). Lectora Inspire mempunyai banyak fitur antaralain animasi, tulisan, gambar, video, dan seterusnya (Agditianingrum et al., 2020). Aplikasi lectora dapat digunakan untuk mengembangkan media pembelajaran interaktif (Upaya Peningkatan Motivasi Dan Hasil Belajar Mahasiswa Dengan Penerapan Model Pembelajaran E-Learning Berbasis Google Classroom Pada Masa Pandemi Covid-19 | Daniati | Jurnal Kependidikan: Jurnal Hasil Penelitian Dan Kajian Kepustakaan Di Bidang Pendidikan, Pengajaran Dan Pembelajaran, n.d.). Pendidik harus menyesuaikan dan menciptakan situasi kondusifpada mahasiswa di masa peralihan pembelajaran daring.tujuan dari penelitian ini agar memudahkan dalam sistem pembelajaran Mahasiswa.

\section{B. Metode}

Penelitiannya menggunakan penelitian Tindakan kelas (PTK) yakni dengan dengan cara menggulang-ulang didalam proses pembelajarannya serta memperbaiki kesalahan yang terjadi hingga benar dan sesuai dengan yang diinginkan. penelitian ini digunakan dengan berkolaborasi antara guru kelas dengan siswa tentang permasalahan dan solusinya (Yuliati et al., 2020). Penelitian ini merefleksikan melalui 4 tahapan biasanya disingkat dengan (4D) yakni perencanaan, tindakan, pengamatan dan refleksi. Subyek penelitian ini dilakukan di pada mahasiswa Semester IVPJKR2019/2020 populasi menggunakan 30 orang mahasiswa terdiri dari 15 laki-laki dan 15 perempuan. Penelitian tindakan kelas ini dilaksanakan berkerjasamadengan 
dosen yang proses dengan bersiklus yakni dengan dua silkus agar mencapai tujuan yang di inginkan. Melalui 4 langkah. Instrumen yang dilakukan antaralain: a) Pemberian angket agar dapat di lakukan evaluasi. b) Melakukan Observasi kelas dengan tujuan mendapatkan gambaran tentang ruang lingkup Perkembangan Motorik. c) Memberikan Angket diharapkan dapat memberikangambaran tentang pandangan mahasiswa agar memperoleh sebuah data informasi, yang digunkan sebagai acuan terhadap permasalahan yang akan ditemui.

\section{Hasil dan Pembahasan}

Diperoleh data pada sebuah penelitian Motorik berupa data kualitatif dan kualitatif melalui angket respon mahasiswa.

Tabel 1. Hasil Validasi Oleh Ahli Materi

\begin{tabular}{|c|c|c|c|}
\hline NO & MATERI & Rata-rata $(\%)$ & KATEGORI \\
\hline \multirow[t]{4}{*}{1} & a. Kesesuain ISI & 90 & valid \\
\hline & b. media & 94 & valid \\
\hline & c. ketepatan & 92 & valid \\
\hline & d. kemutakhiran & 87 & valid \\
\hline \multirow[t]{5}{*}{2} & a. Penyampaian & 89 & valid \\
\hline & b. teknik materi & 91 & valid \\
\hline & c. kelengkapan materi & 88 & valid \\
\hline & d. kemenariakan tampilan & 95 & valid \\
\hline & Rata-Rata & 90,75 & valid \\
\hline
\end{tabular}

hasil validasi ahli materi sebesar 90,75\%. kategori valid.

Tabel 2. Hasil Validasi Oleh Media

\begin{tabular}{llcl} 
NO & MATERI & $\begin{array}{c}\text { RATA-RATA } \\
\text { HASIL }(\%)\end{array}$ & KATEGORI \\
\hline 1 & Tampilan depan & 80,22 & Valid \\
2 & Kesuaian format & 85,24 & Valid \\
3 & Ringkasan isi & 91,36 & Valid \\
4 & Penyajian materi & 90,18 & Valid \\
5 & penampilan & 73,19 & Valid \\
& Rata_Rata & 84,03 & Valid \\
\hline
\end{tabular}

Data hasil validasi oleh ahli media sebesar $84,03 \%$ dengan kreteria valid 
Creating Productive and Upcoming Sport Education Profesional Hmzanwadi University

Vol.4, No.1, Juni 2021, Hal. 50-54

e-ISSN 2614-8781

Tabel 3. Hasil Uji Coba Kelompok Kecil

\begin{tabular}{llcl} 
NO & MATERI & $\begin{array}{l}\text { Rata-Rata } \\
(\%)\end{array}$ & HASIL \\
\hline 1 & Dapat terbaca & 89,27 & Sesuai \\
2 & menarik & 84,12 & Sesuai \\
3 & Bermanfaat & 87,18 & Sesuai \\
& Rata-Rata & 86,85 & Sesuai \\
\hline
\end{tabular}

Hasilnya86,85 dikatakan layak untuk digunakan

\section{Simpulan}

Menurut hasil validasi para ahli dan uji coba kecil dapat disimpulkan bahwa media Lectora layak digunakan dengan rata-rata nilai $87.21 \%$ termasuk dalam kategori "sangat valid". Dan dapat digunakan dalam skala yang lebih luas. maka dapat diajukan dan dilanjutkan untuk semua pihak yang berkepentingan yakni antara lain diharapkan dapat berlanjut ketahap penelitian berikutnya, perlu melakukan kolaborasi dalam penelitian.

\section{Daftar Pustaka}

Agditianingrum, S., Madyono, S., \& Suminah, S. (2020). Peningkatan Hasil Belajar Materi Kegiatan Ekonomi Melalui Media Lectora Inspire Pada Siswa Kelas Iv Sdn Karangtengah 1 Blitar. Wahana Sekolah Dasar, 28 (1), 19-25. Https://Doi.Org/10.17977/Um035v28i12020p019

Dewi, L., Susilawati, S., \& Kurniawan, W. (2020). Pengaruh Media Lectora Inspire Terhadap Kemampuan Berpikir Kritis Siswa Pada Materi Difraksi Dan Interferensi Gelombang Mekanik Kelas Xi Sma. Jurnal Luminous: Riset Ilmiah Pendidikan Fisika, 1(1), 20-26. Https://Doi.Org/10.31851/Luminous.V1i1.3443

Jumesam, J., \& Hariadi, N. (2020). Pengembangan Model Pembelajaran Motorik Untuk Anak Sekolah Dasar. Jurnal Porkes, 3 (2), 119-126.

Kusumah, R. G. T., Walid, A., Pitaloka, S., Dewi, P. S., \& Agustriana, N. (2020). Penerapan Metode Inquiry Sebagai Usaha Untuk Meningkatkan Hasil Belajar Ipa Pada Materi Penggolongan Hewan Di Kelas Iv Sd Seluma. Jurnal Pendidikan Matematika Dan Ipa, 11(1), 142-153. Https://Doi.Org/10.26418/Jpmipa.V11i1.34708

Mahfud, I., \& Fahrizqi, E. B. (2020). Pengembangan Model Latihan Keterampilan Motorik Melalui Olahraga Tradisional Untuk Siswa Sekolah Dasar. Sport Science And Education Journal, 1(1), Article 1. Https://Doi.Org/10.33365/.V1i1.622

Mustafa, P. S., \& Sugiharto, S. (2020). Keterampilan Motorik Pada Pendidikan Jasmani Meningkatkan Pembelajaran Gerak Seumur Hidup. Sporta Saintika, 5(2), 199-218. Https://Doi.Org/10.24036/Sporta.V5i2.133

Noor, S. (2020). Penggunaan Quizizz Dalam Penilaian Pembelajaran Pada Materi Ruang Lingkup Biologi Untuk Meningkatkan Hasil Belajar Siswa Kelas X.6 Sman 7 
Creating Productive and Upcoming Sport Education Profesional Hmzanwadi University

Vol.4, No.1, Juni 2021, Hal. 50-54

e-ISSN 2614-8781

Banjarmasin. Jurnal Pendidikan Hayati, $6 \quad$ (1), $1-7$. Https://Doi.Org/10.33654/Jph.V1i1.927

Pengembangan Media Lectora Inspire Dengan Pendekatan Kontekstual Pada Siswa Sma Kelas $X \mid$ Zuhri | Pythagoras: Jurnal Program Studi Pendidikan Matematika. (N.D.). Retrieved January 16 , 2021 , From Https://Www.Journal.Unrika.Ac.Id/Index.Php/Jurnalphythagoras/Article/View/463

Shalikhah, N. D. (2017). Media Pembelajaran Interaktif Lectora Inspire Sebagai Inovasi Pembelajaran. Warta Lpm, 20(1), 9-16. Https://Doi.Org/10.23917/Warta.V19i3.2842

Upaya Peningkatan Motivasi Dan Hasil Belajar Mahasiswa Dengan Penerapan Model Pembelajaran E-Learning Berbasis Google Classroom Pada Masa Pandemi Covid-19| Daniati | Jurnal Kependidikan: Jurnal Hasil Penelitian Dan Kajian Kepustakaan Di Bidang Pendidikan, Pengajaran Dan Pembelajaran. (N.D.). Retrieved January 16, 2021,Https://Ojs.Ikipmataram.Ac.Id/Index.Php/Jurnalkependidikan/Article/View/2642

Yuliati, N. M., Hente, A., \& Nurmiati, N. (2020). Meningkatkan Kemampuan Motorik Halus Anak Melalui Kegiatan Menghubungkan Titik Dengan Menggunakan Media Tulis Di Kelompok A Paud Al Musafir Palu Barat. Jurnal Kolaboratif Sains, 1(1), Article 1. Https://Doi.Org/10.31934/Jom.V1i1.1270 